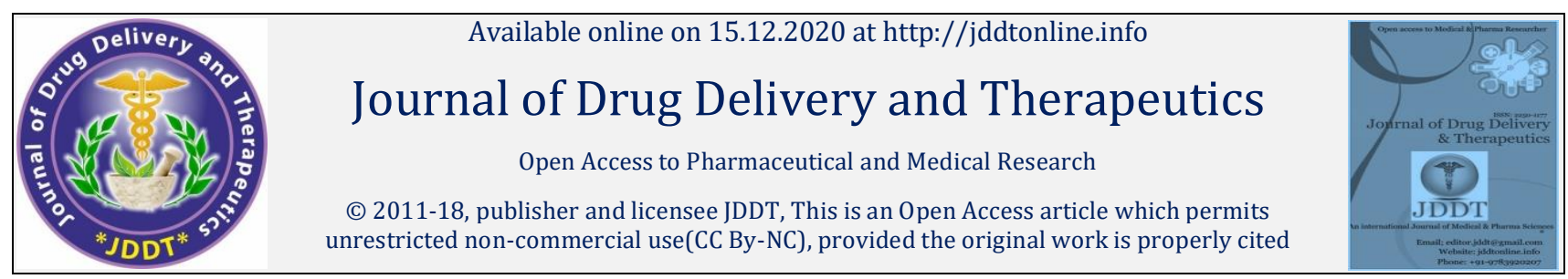

Open 1 Access

Mini Review

\title{
Oral Gene Delivery: An Innovative Approach for Colorectal Center Therapy
}

\author{
Meghna Patel, Kinjal Patel*, Devanshi Patel \\ M. B. Patel Science College, B.Sc. Microbiology Department, Anand Gujarat India
}

\begin{abstract}
Colorectal cancer is the third most commonly diagnosed cancer in the world characterized by neoplasia in the colon, rectum, or vermiform appendix. Current treatment approaches include chemotherapy, radiotherapy and surgery however non-specific bio-distribution of anti-cancer drug, lack of effective and safe drug delivery career, drug resistance and relapse are major limiting factors of current therapy. Gene therapy is a technique for correcting defective genes responsible for disease development. The future of gene therapy depends on achieving successful delivery of wild type gene to replace a faulty gene. Recently, there has been an increasing interest in delivery of drugs and gene via the gastrointestinal tract. Gene therapy via this route has many advantages, including non-invasive access and the versatility to treat local diseases, such as inflammatory bowel disease, colorectal cancer, as well as systemic diseases, such as haemophilia. However, the intestine presents several distinct barriers and, therefore, the design of robust non-viral delivery systems is key to future success. The review covers obstacles in the path of successful gene therapy using oral route to treat colorectal cancer as well as strategies to overcome.
\end{abstract}

Keywords: Colorectal cancer, Oral gene delivery, Targeted delivery

Article Info: Received 09 Oct 2020; $\quad$ Review Completed 19 Nov 2020; $\quad$ Accepted 30 Nov 2020; $\quad$ Available online 15 Dec 2020

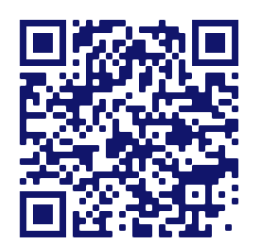

Cite this article as:

Patel M, Patel K, Patel D, Oral Gene Delivery: An Innovative Approach for Colorectal Center Therapy, Journal of Drug Delivery and Therapeutics. 2020; 10(6-s):186-188 http://dx.doi.org/10.22270/jddt.v10i6-s.4424

*Address for Correspondence:

Kinjal Patel, M. B. Patel Science College, B.Sc. Microbiology Department, Anand Gujarat India

\section{Introduction}

The future of nucleic acid-based therapeutics is dependent on achieving successful delivery. Recently, there has been an increasing interest in delivery via the gastrointestinal tract. Gene therapy via this route has many advantages, including non-invasive access and the versatility to treat local diseases, such as inflammatory bowel disease, colorectal cancer, as well as systemic diseases, such as haemophilia. However, the intestine presents several distinct barriers and, therefore, the design of robust non-viral delivery systems is key to future success ${ }^{1-4}$.

Several characteristics of the GIT make it an attractive target for gene therapy applications. First, the gut is readily accessible either by oral, rectal or endoscopic methods, facilitating access to target tissues without the need for invasive surgery5,6. The oral route is of particular interest owing to high patient compliance and reduced healthcare cost. The large surface area of the gut means that a large population of cells are available for uptake. Another advantage to gut gene delivery is the presence of stem cells in the crypts of Lieberkuhn ${ }^{7-9}$. These might be of particular interest in certain gene therapy applications as their successful transfection could, in some circumstances, facilitate long-term expression of therapeutic genes. Finally, the gut epithelium is highly vascularised, being located only a few microns from an extensive capillary network. The potential delivery of nucleic acid therapies themselves to distant disease sites (e.g. tumours) following transport across the intestinal epithelial barrier (by transcellular or paracellular routes) is also of interest figure 1.110-12. Local conditions that might be treatable by gene therapy include inflammatory bowel disease (IBD), familial adenomatous polyposis (FAP), intestinal cancers and the intestinal symptoms of cystic fibrosis. The use of orally delivered DNA vaccines is also an area of intense interest given the presence of the gut-associated lymphoid tissue (GALT) and the range of pathogens to which the gut is exposed. Of particular interest to DNA vaccine applications are the antigensampling M-cells found in the follicle-associated epithelium (FAE) of lymphoid follicles and Peyer's patches ${ }^{13-16}$.

\section{Obstacles to intestinal gene delivery and cellular targets:}

Whereas the GIT presents several opportunities for gene therapy, several extracellular and cellular barriers exist that can limit therapeutic success. An ideal gene delivery vector (GDV) would need to survive in the extracellular milieu and efficiently transfect or traverse the mucosal epithelium, depending on therapeutic strategy ${ }^{17-19}$.

CODEN (USA): JDDTAO 


\section{Extracellular barriers}

If a gene therapeutic is administered orally, then the first major obstacle it faces is the harsh acidic (pH 1.5-1.9) environment of the stomach. Additionally, $\mathrm{pH}$ values in the small and large intestine can be variable and, therefore, GDV stability over a wide $\mathrm{pH}$ range is necessary. Indeed, nucleic acids are known to be denatured and depurinated over time in acidic gastric media, decreasing their effectiveness. In addition, the presence of the proteolytic gastric enzyme pepsin might impact GDV stability. The fluid flow and peristaltic activity of the GIT might also reduce the contact time between GDVs and the epithelial layer, thereby limiting the opportunities for uptake. Nuclease enzymes are present in the GIT lumen and might degrade nucleic acids before cellular entry. Another barrier to GDV delivery is the glycocalyx ; a glycoprotein and polysaccharide layer (400$500 \mathrm{~nm}$ thick) associated with the apical membrane of enterocytes. It acts as a size-selective diffusional barrier preventing access of certain viruses, bacteria and particles to the underlying plasma membrane $20-22$.

\section{Cellular barriers and targets}

Several obstacles to GDV uptake are presented by the epithelial barrier. Depending on the gene therapy application, transfection or knockdown of a gene in the epithelial cells themselves might be the goal, or else direct access to the underlying lamina propria might be desired. In relation to the latter, GDVs primarily cross the epithelium either between the cells (paracellular route) or through the cells (transcellular route) figure 1.123-25. The paracellular transport of GDVs is limited by the presence of tight junctions (TJs) between cells. Indeed, the paracellular pore size in the human intestine generally lies within the $0.5-3$ $n m$ range, which is smaller than the size of most GDVs ${ }^{26-30}$. The transcellular route of transport is advantageous owing to the extensive surface area for uptake. In terms of the transcellular transport of GDVs, the main mechanism is transcytosis. This involves the endocytosis of the GDV at the apical membrane of the intestinal epithelial cells (IECs), its transport through the cell and across the basolateral membrane into the underlying lamina propria31-34. Several endocytic mechanisms exist by which GDVs can enter IECs. Intracellular barriers also exist and include the presence of nucleases, the possibility of GDV recycling back to the lumen and nuclear uptake in the case of pDNA strategies where IEC transfection is desired. Epithelial cells have a short lifetime of 5-7 days, being continuously shed and replaced. Therefore, repeated administrations of gene therapies might be necessary when these cells are targeted $35-37$.

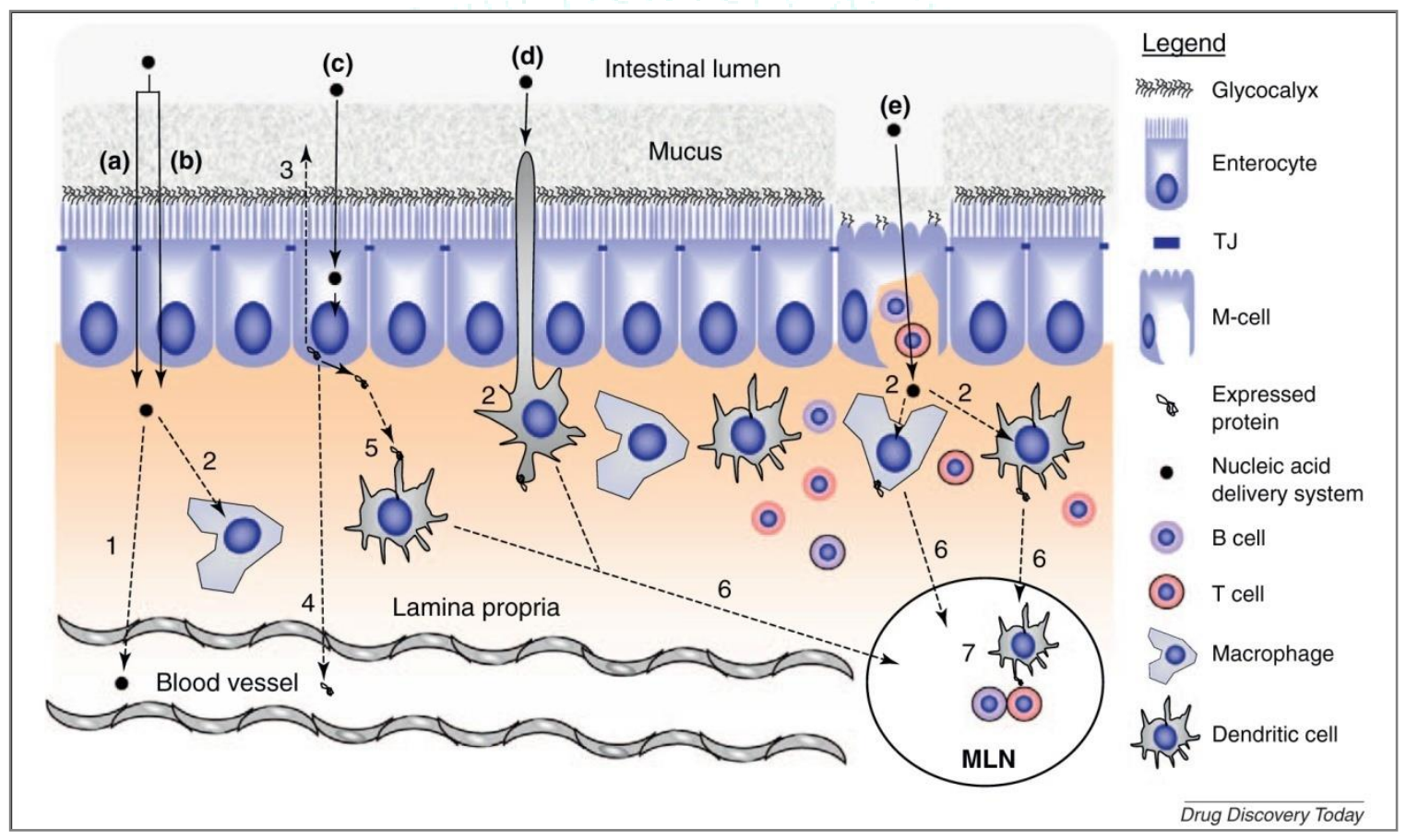

Figure 1: Uptake and/or transport of GDVs by the intestinal epithelium and induction of biological effect(s).

GDVs can gain access to the lamina propria by (a) the paracellular route or via transcytosis through (b) enterocytes or (e) M-cells. Alternatively, dendritic cells potentially facilitate GDV transport across the epithelium (d). The GDVs can subsequently (1) gain access to the systemic circulation or (2) transfect lamina propria cells. (c) GDVs can also transfect epithelial cells and expressed therapeutic proteins might enter the lumen (3) or be secreted basolaterally (4) and enter the bloodstream or (5) be processed by lamina propria cells. In terms of DNA vaccines, APCs that have the expressed antigenic protein [either through (2) their direct transfection or (5) protein processing can migrate to the mesenteric lymph nodes (MLNs) (6) and induce T and B cell differentiation and/or activation (7). These immunocompetent cells can enter into the systemic circulation and mucosal tissues, generating systemic and mucosal immunity38-41.

\section{Conclusion}

CRC is one the major worldwide health problems owing to its high prevalence and mortality rates. It is reported that over 40000 of the adult United Kingdom population are diagnosed with CRC each year. In case of early diagnosis CRC is also one of the most curable types of cancer (cure rates $>$ $90 \%$ ). However, increased understanding of the molecular mechanisms underlying carcinogenesis has spurred focus on the development and incorporation of molecular targeted agents in current therapeutic options for CRC. Further research to explain the molecular pathology of CRC may 
improve treatment options and the long term survival of patients.

\section{References}

1. O'Neill MJ, Bourre L, Melgar S, O'Driscoll CM. Intestinal delivery of non-viral gene therapeutics: physiological barriers and preclinical models. Drug discovery today. 2011;16(5-6):203-18.

2. Fearon ER, Vogelstein B. A genetic model for colorectal tumorigenesis. Cell. 1990;61(5):759-67.

3. Bhatt P, Lalani R, Mashru R, Misra A. Abstract 2065: Anti-FSHR antibody Fab' fragment conjugated immunoliposomes loaded with cyclodextrin-paclitaxel complex for improved \&lt;em\&gt; in vitro\&lt;/em\&gt; efficacy on ovarian cancer cells. Cancer Research. 2016;76(14 Supplement):2065.

4. Ilyas M, Straub J, Tomlinson IP, Bodmer WF. Genetic pathways in colorectal and other cancers. European journal of cancer (Oxford, England : 1990). 1999;35(3):335-51.

5. Compton CC, Greene FL. The staging of colorectal cancer: 2004 and beyond. CA: a cancer journal for clinicians. 2004;54(6):295308.

6. Sancho E, Batlle E, Clevers H. SIGNALING PATHWAYS IN INTESTINAL DEVELOPMENT AND CANCER. Annual Review of Cell and Developmental Biology. 2004;20(1):695-723.

7. Pinto D, Clevers H. Wnt, stem cells and cancer in the intestine. Biology of the cell. 2005;97(3):185-96.

8. Bhatt P, Vhora I, Patil S, Amrutiya J, Bhattacharya C, Misra A, et al. Role of antibodies in diagnosis and treatment of ovarian cancer: Basic approach and clinical status. J Control Release. 2016;226:148-67.

9. Strate LL, Syngal S. Hereditary colorectal cancer syndromes. Cancer causes \& control : CCC. 2005;16(3):201-13.

10. Croce CM. Oncogenes and Cancer. New England Journal of Medicine. 2008;358(5):502-11.

11. Kaler P, Galea V, Augenlicht L, Klampfer L. Tumor associated macrophages protect colon cancer cells from TRAIL-induced apoptosis through IL-1beta-dependent stabilization of Snail in tumor cells. PloS one. 2010; 5(7):e11700.

12. Lalani RA, Bhatt $P$, Rathi M, Misra A. Abstract 2063: Improved sensitivity and in vitro efficacy of RGD grafted PEGylated gemcitabine liposomes in RRM1 siRNA pretreated cancer cells. Cancer Research. 2016; 76(14 Supplement):2063.

13. Astin M, Griffin T, Neal RD, Rose P, Hamilton W. The diagnostic value of symptoms for colorectal cancer in primary care: a systematic review. The British journal of general practice : the journal of the Royal College of General Practitioners. 2011; 61(586):e231-43.

14. Fearon ER. Molecular genetics of colorectal cancer. Annual review of pathology. 2011; 6:479-507.

15. Hemal Tandel PB, Keerti Jain, Aliasgar Shahiwala, Ambikanandan Misra. In-Vitro and In-Vivo Tools in Emerging Drug Delivery Scenario: Challenges and Updates. In: Misra ASaA, editor. In-Vitro and In-Vivo Tools in Drug Delivery Research for Optimum Clinical Outcomes: CRC Press; 2018.

16. Chen MJ, Cheng YM, Lai PH, Wu JF, Hsu YC. In vitro biocompatibility of thermally gelling liquid mucoadhesive loaded curcuminoids in colorectal cancer chemoprevention. International journal of colorectal disease. 2012; 27(7):869-78.

17. Burn J, Mathers J, Bishop DT. Genetics, inheritance and strategies for prevention in populations at high risk of colorectal cancer (CRC). Recent results in cancer research Fortschritte der Krebsforschung Progres dans les recherches sur le cancer. 2013; 191:157-83.

18. Javia A, Amrutiya J, Lalani R, Patel V, Bhatt P, Misra A. Antimicrobial peptide delivery: an emerging therapeutic for the treatment of burn and wounds. Ther Deliv. 2018; 9(5):375-86.

19. Mishra J, Drummond J, Quazi SH, Karanki SS, Shaw JJ, Chen B, et al. Prospective of colon cancer treatments and scope for combinatorial approach to enhanced cancer cell apoptosis. Critical reviews in oncology/hematology. 2013; 86(3):232-50.

20. Vatandoust S, Price TJ, Karapetis CS. Colorectal cancer: Metastases to a single organ. World journal of gastroenterology. 2015; 21(41):11767-76.

21. Patel P, Hanini A, Shah A, Patel D, Patel S, Bhatt P, et al. Surface Modification of Nanoparticles for Targeted Drug Delivery. In: Pathak YV, editor. Surface Modification of Nanoparticles for
Targeted Drug Delivery. Cham: Springer International Publishing; 2019. p. 19-31.

22. Bray F, Ferlay J, Soerjomataram I, Siegel RL, Torre LA, Jemal A. Global cancer statistics 2018: GLOBOCAN estimates of incidence and mortality worldwide for 36 cancers in 185 countries. CA: a cancer journal for clinicians. 2018; 68(6):394-424.

23. Sharma G, Sharma AR, Lee SS, Bhattacharya M, Nam JS, Chakraborty C. Advances in nanocarriers enabled brain targeted drug delivery across blood brain barrier. International journal of pharmaceutics. 2019; 559:360-72.

24. Patel J, Amrutiya J, Bhatt P, Javia A, Jain M, Misra A. Targeted delivery of monoclonal antibody conjugated docetaxel loaded PLGA nanoparticles into EGFR overexpressed lung tumour cells. J Microencapsul. 2018; 35(2):204-17.

25. Silva CO, Pinho JO. Current Trends in Cancer Nanotheranostics: Metallic, Polymeric, and Lipid-Based Systems. 2019; 11(1).

26. Ehrlich P, Himmelweit F. The collected papers of Paul Ehrlich : in four volumes, including a complete bibliography. London; New York: Pergamon Press; 1956.

27. Hansch C, Leo A, Hoekman D, editors. Exploring QSAR: Hydrophobic, electronic, and steric constants. Washington, DC: American Chemical Society; 1995.

28. Martin YC. Exploring QSAR: Hydrophobic, Electronic, and Steric Constants C. Hansch, A. Leo, and D. Hoekman. American Chemical Society, Washington, DC. 1995 . Xix + 348 pp. $22 \times 28.5$ $\mathrm{cm}$. Exploring QSAR: Fundamentals and Applications in Chemistry and Biology. C. Hansch and A. Leo. American Chemical Society, Washington, DC. 1995 . Xvii +557 pp. $18.5 \times$ $26 \mathrm{~cm}$. ISBN 0-8412-2993-7 (set). \$99.95 (set). Journal of Medicinal Chemistry. 1996; 39(5):1189-90.

29. Bhatt P, Fnu G, Bhatia D, Shahid A, Sutariya V. Nanodelivery of Resveratrol-Loaded PLGA Nanoparticles for Age-Related Macular Degeneration. AAPS PharmSciTech. 2020; 21(8):291.

30. Dhanikula AB, Panchagnula R. Localized paclitaxel delivery. International journal of pharmaceutics. 1999; 183(2):85-100.

31. Seedher N, Bhatia S. Solubility enhancement of Cox-2 inhibitors using various solvent systems. AAPS PharmSciTech. 2003; 4(3):E33-E.

32. Achim M, Tomuta I, Vlase L, Iuga C, Moldovan M, Leucuta SE. Paclitaxel-loaded poly(lactic-co-glycolic acid) microspheres: preparation and in vitro evaluation. Journal of Drug Delivery Science and Technology. 2008; 18(6):410-6.

33. Manish G, Vimukta S, editors. Targeted drug delivery system: A Review2011.

34. Narvekar P, Bhatt P, Fnu G, Sutariya V. Axitinib-Loaded Poly(Lactic-Co-Glycolic Acid) Nanoparticles for Age-Related Macular Degeneration: Formulation Development and In Vitro Characterization. ASSAY and Drug Development Technologies. 2019; 17(4):167-77.

35. Tapeinos C, Battaglini M, Ciofani G. Advances in the design of solid lipid nanoparticles and nanostructured lipid carriers for targeting brain diseases. Journal of controlled release : official journal of the Controlled Release Society. 2017; 264:306-32.

36. Vhora I, Lalani R, Bhatt P, Patil S, Patel H, Patel V, et al. Colloidally Stable Small Unilamellar Stearyl Amine Lipoplexes for Effective BMP-9 Gene Delivery to Stem Cells for Osteogenic Differentiation. AAPS PharmSciTech 2018; 19:3550-60.

37. Raucher D, Dragojevic S, Ryu J. Macromolecular Drug Carriers for Targeted Glioblastoma Therapy: Preclinical Studies, Challenges, and Future Perspectives. Frontiers in oncology. 2018; 8:624.

38. Goel A, Baboota S, Sahni JK, Ali J. Exploring targeted pulmonary delivery for treatment of lung cancer. Int J Pharm Investig. 2013;3(1):8-14.

39. Ding J, Feng M, Wang F, Wang H, Guan W. Targeting effect of PEGylated liposomes modified with the Arg-Gly-Asp sequence on gastric cancer. Oncology reports. 2015; 34(4):1825-34.

40. Patil S, Lalani R, Bhatt P, Vhora I, Patel V, Patel $\mathrm{H}$, et al. Hydroxyethyl substituted linear polyethylenimine for safe and efficient delivery of siRNA therapeutics. RSC Advances. 2018; 8(62):35461-73.

41. Xie J, Xiao D, Zhao J, Hu N, Bao Q, Jiang L, et al. Mesoporous Silica Particles as a Multifunctional Delivery System for Pain Relief in Experimental Neuropathy. Adv Healthc Mater. 2016; 5(10):1213-21. 